\begin{tabular}{|l|l|}
\hline $\begin{array}{l}\text { Anuario da Facultade de Dereito da UDC } \\
\text { (AFDUDC) }\end{array}$ & $\begin{array}{l}\text { Vol. 20 (2016) pp. 72-97 } \\
\text { ISSN-e } \\
\text { DOI }\end{array}$ \\
\hline
\end{tabular}

\title{
LA EVOLUCIÓN DE LA REGULACIÓN DEL ABORTO EN ESPAÑA: PERSPECTIVAS TEÓRICAS Y PROYECCIÓN NORMATIVA
}

\author{
DANIEL CAPODIFERRO CUBERO \\ Investigador postdoctoral \\ Departamento de Ciencia Política y Derecho Público \\ Universidad Autónoma de Barcelona
}

Fecha de recepción: 30.6 .2016

Fecha de aceptación: 6.9.2016

\begin{abstract}
Resumen: El presente artículo plantea un recorrido por las distintas fórmulas de regulación de la interrupción voluntaria del embarazo desde un punto de vista teórico y jurídico. Para ello, tras una primera parte dedicada a describir las distintas aproximaciones teóricas que, en términos generales, fundamentan las diferentes opciones normativas, se repasan las pautas jurisprudenciales que se derivan de las resoluciones del Tribunal Europeo de Derechos Humanos, pasando después a plantear el contenido de las distintas soluciones normativas, pasadas o vigentes, mediante las que se ha articulado esta cuestión en el Ordenamiento español, incluyendo la última iniciativa legislativa, fallida, planteada por el Gobierno en 2013, cuyos términos son objeto de un análisis particular centrado en los problemas teóricos y prácticos que habría planteado de haber llegado a aprobarse.
\end{abstract}

Palabras clave: Aborto legal; Interrupción voluntaria del embarazo; Modelos de despenalización; Salud reproductiva; Derechos de las mujeres; Derecho a la vida.

Abstract: This article aims to expose the different theoretical and regulatory solutions can be adopted for the voluntary termination of pregnancy. After a brief introduction about the basis of the different normative approaches, there is a review of the jurisprudential guidelines developed by the European Court of Human Rights about this issue and, hereafter, an overview of the content of the national regulations, past and present, and the jurisprudence of the Constitutional Court. It is included the last failed legal initiative about abortion raised by the Government in 2013, whose terms are 
subject to a particular analysis focused on the theoretical and practical problems that would have raised if it would have been approved.

Keywords: Legal abortion; Voluntary termination of pregnancy; Decriminalization models; Reproductive health;. Women's rights; Right to life.

SUMARIO: I. INTRODUCCIÓN. II. APROXIMACIONES TEÓRICAS Y MODELOS DE DESPENALIZACIÓN. III. LA INTERRUPCIÓN DEL EMBARAZO EN EL ÁMBITO DEL CONSEJO DE EUROPA Y LA UNIÓN EUROPEA. IV. EVOLUCIÓN NORMATIVA ANTERIOR A LA CONSTITUCIÓN DE 1978. 1. De la Edad Media a la Codificación. 2. La regulación en la II República. V. EL MODELO DESPENALIZADOR DE LA LO 9/1985. 1. Descripción del sistema. 2. La valoración del Tribunal Constitucional. VI. EL SISTEMA DE LA LO 2/2010. VII. EL INTENTO DE REFORMA DEL ANTEPROYECTO DE LO PARA LA PROTECCIÓN DE LA VIDA DEL CONCEBIDO DE 2013. VIII. CONCLUSIONES.

\section{INTRODUCCIÓN}

La despenalización de la interrupción voluntaria del embarazo es, quizá, el ejemplo más evidente de proyección jurídica de una controversia ética que en el Ordenamiento español se puede apreciar con especial nitidez. En el fondo, el debate que subyace a las distintas soluciones normativas que se pueden plantear o se han planteado no confronta distintas opiniones sobre la misma realidad, sino la preeminencia de un determinado valor positivo ${ }^{1}$, que en última instancia será la vida (en un sentido amplio e, incluso, ambiguo) o la libertad individual (de un sujeto consciente, normalmente la gestante); ambos valores se defienden en términos absolutos o con aspiración de serlo.

A esto se suma que la mayoría de la doctrina viene haciendo depender la solución a este conflicto, en última instancia, de la condición del concebido no nacido como un ser vivo, lo que añade una dificultad a la cuestión: encontrar el momento exacto de inicio de la vida humana dependiente, que implicará la adquisición de personalidad por parte del nasciturus ${ }^{2}$, siempre y cuando se entienda que estar vivo y ser persona son términos equivalentes, cosa que también suscita dudas.

Pero se trata de una aproximación errónea al problema. La esencia del debate sobre el aborto reside en el desacuerdo existente sobre cuál es la interpretación correcta

\footnotetext{
${ }^{1}$ FERRATER MORA, J.; COHN, P. Ética aplicada. Del aborto a la violencia, Madrid, 1982, p. 41.

${ }^{2}$ Como señala RUIZ MIGUEL, A. El aborto: problemas constitucionales, Madrid, 1990, p. 34-35 se trata más de determinar la personalidad moral del feto que su personalidad jurídica. Aunque en ocasiones se ha empleado esta segunda categoría para incidir en la falta de personalidad del no nacido, los argumentos relevantes en el debate, sostiene el autor, deben ser de tipo moral, dada la insuficiencia de los meramente jurídicos para revocar unos argumentos morales que les fueran contrarios.
} 
de la idea del valor intrínseco del concebido no nacido que, en abstracto y como concepto, es comúnmente aceptada ${ }^{3}$. No se trata de averiguar si el feto tiene intereses propios y esos intereses están por encima o no de los de la gestante. La pregunta esencial es si está justificado frustrar una realidad biológica en desarrollo para evitar hacer lo propio con una vida, la de la mujer, en la que además del elemento biológico ya existe un desarrollo social y humano ${ }^{4}$ y si se responde afirmativamente, en qué casos sería eso admisible.

Se llega así a una valoración entre el elemento biológico y el elemento cultural o vivencial de la existencia. Esto no soluciona directamente la controversia, porque se pueden seguir defendiendo conclusiones muy diferentes, pero la lleva a términos más objetivos: si bien no todo el mundo opinará que el nasciturus esté vivo, sí habrá más acuerdo en reconocer que, en sí mismo, es digno de algún tipo de protección. Trasladando esto al plano jurídico, se trataría de determinar qué respuesta puede o debe dar el Derecho en aquellas situaciones en las que la continuación de un embarazo entre en conflicto con los derechos o intereses de la mujer que, además del elemento biológico, ya posee un desarrollo social y humano. Todo ello teniendo en cuenta que los parámetros morales en los que puede moverse el Poder Público son los de la ética pública, entendida como el mínimo valorativo comúnmente aceptado por la sociedad que, bajo la forma de criterios de organización de la vida social, valores, principios y derechos, permita a los ciudadanos desarrollar su dignidad y escoger su moralidad privada, sin imposiciones ${ }^{5}$. Por tanto, la tarea del Ordenamiento en este ámbito es la de aportar soluciones o, al menos, reglas que permitan realizar la debida ponderación de los derechos, valores o intereses presentes en cada caso, sin llegar a negar de manera absoluta ninguno de los intereses que entran en conflicto, aparentemente, irresoluble por otra vía que no sea el sacrificio de uno de ellos.

\section{APROXIMACIONES TEÓRICAS Y MODELOS DE DESPENALIZACIÓN}

A pesar de lo dicho, toda norma que aborde esta cuestión va a posicionarse, y a contener inevitablemente, una determinada concepción de la libertad individual de la mujer, del fenómeno de la sexualidad y la procreación y del valor de la vida en formación, que articulará con el objetivo de aportar reglas que permitan su ponderación en la práctica de modo que puedan solucionarse casos concretos. Así, las soluciones normativas se han movido entre dos grandes concepciones teóricas, aportando dos definiciones alternativas de qué es la interrupción voluntaria del embarazo para el Derecho.

La primera es la heredera de los argumentos que se formulan para defender la inmoralidad del aborto, planteando que la interrupción del embarazo es, por definición y en general, una conducta ilícita de tal gravedad que debe ser regulada por el Derecho Penal. Ésta será la rama del Ordenamiento encargada no sólo de recoger los castigos que correspondan por su realización, sino también de establecer las posibles

\footnotetext{
${ }^{3}$ DWORKIN, R. El Dominio de la vida, Barcelona, 1998, p. 91 s.

${ }^{4}$ Ibídem, p. 126.

${ }^{5}$ PECES-BARBA, G. "Ética pública-ética privada”, Anuario de Filosofía del Derecho, XIV, 1997, p. 536 S.
} 
excepciones tasadas que, de concurrir, harán que la conducta de la mujer y del profesional sanitario que lleva a cabo la intervención no sean punibles. Así, el sistema se define a partir de la noción de ilícito, concibiendo la interrupción del embarazo como una situación fuera de lo normal.

En las regulaciones que optan por esta solución son evidentes las reminiscencias de planteamientos de base religiosa, eminentemente de la moral católica, para la que con independencia del momento de desarrollo y de posibles taras físicas o psíquicas, el no nacido siempre es persona y, como tal, es titular del derecho fundamental a la vida con la misma intensidad que la gestante, lo que lleva a condenar toda privación de la misma como algo moralmente reprobable en cualquier circunstancia ${ }^{6}$. No obstante, también existen argumentaciones, y por tanto fundamentaciones posibles para una concepción de la interrupción del embarazo como un "mal puntualmente inevitable", alejadas del pensamiento de base religiosa, como la que plantea la prohibición de la interrupción voluntaria del embarazo como regla general con la finalidad de dar cumplimiento a los principios bioéticos de no maleficencia y justicia a partir de la siguiente premisa ${ }^{7}$ : no existe un derecho de la gestante (ni, obviamente del Estado) a disponer de la existencia del concebido no nacido ya que éste es un ser individualizable genéticamente y un organismo individual físicamente íntegro que debe ser valorado no como un ser humano en potencia, sino como un ser humano completo con potencial con iguales derechos que un adulto, a lo que se suma el hecho, determinante, de ser un inocente.

La visión contraria articula el discurso jurídico a partir de la libertad de la mujer y las connotaciones que el embarazo no deseado puede tener para su dignidad y el libre desarrollo de su personalidad. Un sistema fundado en esta concepción defenderá que el acceso a la interrupción del embarazo es un derecho de la gestante y nunca la excepción a una conducta prohibida, tratándolo como una opción legítima de la mujer fruto del ejercicio de la propia autonomía. No obstante, esto no impide que su ejercicio deba estar sometido a determinadas condiciones para preservar otros derechos, bienes jurídicos o intereses dignos de protección que puedan verse afectados, ya que no existen derechos ilimitados. Así concebido, el aborto, lejos de ser un fenómeno ajeno al Derecho, se caracteriza como una posibilidad que el Ordenamiento ofrece a la mujer para que, si lo desea y cumple los requisitos que se establezcan normativamente, haga uso de ella. En este caso, la intervención de la Ley Penal es subsidiaria: la regulación de la interrupción del embarazo no será, en la determinación de su régimen jurídico, competencia de esa rama del Derecho, a la que sólo habrá que recurrir para perseguir aquellas conductas que se hayan alejado de las reglas establecidas.

Sin ánimo de exhaustividad, los planteamientos teóricos que sustentan esta visión son variados y se mueven desde los que defienden que la destrucción del nasciturus es un acto moralmente inocuo al no tratarse de un ser vivo ${ }^{8}$, hasta los que argumentan que, a partir de criterios de oportunidad, prohibir la interrupción del embarazo o someterla a leyes especialmente restrictivas genera más perjuicios que beneficios porque, lejos de impedirlas, envía estas actuaciones a la clandestinidad con el

\footnotetext{
${ }^{6}$ IBÁÑEZ Y GARCÍA-VELASCO, J.L.. La despenalización del aborto voluntario en el ocaso del siglo $X X$. Madrid, 1992, p. $148 \mathrm{~s}$.

7 Vid. FINNIS, J. "Abortion and Health Care Ethics", en VV. AA. Bioethics. An Anthology (Ed. por Kuhse, H.; Singer, P.), Oxford, 1999, p. 13 s.

${ }^{8}$ SINGER, P. Ética Práctica, $3^{\text {a }}$ Ed, Trad. de Guastavino, M. I., Barcelona, 1991. p. 144-145.
} 
consiguiente aumento de riesgos y dificultades para la gestante ${ }^{9}$. Aun así, la línea más comúnmente asumida a este respecto es la que define la posibilidad de interrumpir el embarazo como una proyección del derecho de la mujer a disponer del propio cuerpo ${ }^{10}$, algo posible en la medida en que la maternidad es un deber que se podría calificar como relativo, ya que su cumplimiento ha de ser valorado como un mérito, pero su incumplimiento no puede ser considerado una falta ${ }^{11}$ : en estos términos, el nasciturus, con independencia de que se considere o no vivo, carece de derecho alguno a disponer del cuerpo de otra persona de manera continuada, aun cuando esto fuera condición necesaria para su supervivencia, se tratase de un periodo de tiempo pequeño o supusiera una carga menor para la persona cuyo cuerpo se va a utilizar ${ }^{12}$, y en la medida en que a ningún sujeto libre, la embarazada en este caso, se le puede exigir que sacrifique su vida, en el caso de embarazos de riesgo vital, o renuncie a su salud o a los distintos aspectos de su existencia libre, durante el tiempo que sea con el fin que sea, si no desea hacerlo, negarse a hacerlo no puede considerarse como algo injusto (aunque hacerlo sí sería un acto loable). Aunque, en sentido contrario, si continuar con un embarazo buscado no supone un verdadero sacrificio y la pretensión de interrumpirlo está motivada por capricho o interés pasajero ésta no se podría considerar legítima, puesto que con su conducta anterior la mujer ha generado una responsabilidad clara que permite exigirle coherencia en su comportamiento.

Por supuesto, cada una de estas dos opciones tiene una vertiente extrema, asociada a la fórmula más radical de la postura ideológica que la sustenta, que no hay que identificar sin más con el planteamiento del que deriva. En el caso de la primera, la prohibición absoluta de abortar bajo cualquier circunstancia. En la segunda, el reconocimiento de la posibilidad de interrumpir el embarazo de manera libre e incondicionada en cualquier momento. Pero mientras la primera de estas visiones radicales ha sido la tónica dominante hasta el s. XX, los ejemplos de la segunda son testimoniales ${ }^{13}$, predominando actualmente los enfoques intermedios.

\footnotetext{
${ }^{9}$ Vid. RUIZ MIGUEL, A. El aborto... cit. p. 74. El problema de este argumento es que es una objeción frente a la conveniencia de las leyes que prohíben la interrupción del embarazo, pero no aborda la justificación o moralidad del hecho; plantea razones de política jurídica que bien pueden servir de apoyo a argumentos favorables a la elección, pero no tienen peso por sí mismas en un debate moral

${ }^{10}$ Cosa que desde las corrientes de pensamiento feminista se ha llegado a caracterizar como un paso más en la liberación sexual frente al control masculino. A este respecto, TONG, R. Feminist Thought. A Comprehensive Introduction, $6^{\mathrm{a}}$ Reimp., Londres, 1997. p. 72-74.

${ }^{11}$ LÓPEZ DE LA VIEJA, M. T.. La mitad del mundo (Ética y Crítica feminista). Salamanca, 2004, p. 64 S.

${ }^{12}$ Es la tesis de THOMSON, J.J. "Una defensa del aborto" en VV. AA., Debate sobre el aborto. Cinco ensayos de filosofía moral, $2^{\mathrm{a}}$ Ed., Madrid, 1992. p. 9 s. Traducción al castellano del original, publicado en Philosophy and Public Affairs, $\mathrm{n}^{\circ} 1,1971$. Una revisión del planteamiento de Thomson niega que la mujer tenga derecho alguno a destruir al feto, ya que no es parte de su cuerpo ni su propiedad; es más, nadie tiene derecho a destruirlo aunque se considere que no tiene derecho a la vida. Pero por otro lado, también rechaza que exista un derecho del feto a ocupar el útero materno, generándose un conflicto que resultaría insalvable a no ser por los avances en las técnicas reproductivas que permiten la extracción del feto sin destruirlo para que pueda continuar con su desarrollo mediante su implantación en otra mujer o in vitro. Por tanto, la solución, casi única, al problema estaría en recurrir a esta salida para respetar tanto la autonomía de la mujer como el bien del no nacido. Vid. OVERALL, C. Ethics and Human Reproduction. A Feminist Analysis. Boston, 1987, p. $68 \mathrm{~s}$.

${ }^{13} \mathrm{El}$ aborto configurado como derecho absoluto e ilimitado de la mujer se dio en la Unión Soviética entre 1920, fecha de su legalización, y 1936, momento en el que la Ordenanza de 27 de junio lo vuelve a considerar delito en todo caso.
} 
A partir de la tesis jurídico-moral a la que se adhiera el Poder Público, el Derecho establecerá las pautas concretas, formales y materiales, que determinarán cuándo será posible practicar un aborto legalmente, conformando lo que se puede denominar un modelo o sistema de despenalización, basado en reglas temporales (plazo) o materiales (indicaciones).

En un sistema de plazo se permite interrumpir el embarazo hasta una determinada fecha dentro del periodo de gestación sin otra condición esencial que la voluntad manifestada por la mujer a través de los cauces reglados. Se suelen contemplar también circunstancias excepcionales que permiten ampliar el tiempo para realizar la intervención, siendo la más habitual el peligro vital. Este modelo quizá responda mejor a una concepción del aborto como derecho, pero igualmente puede dar lugar a un régimen jurídico muy restrictivo si los plazos son, por ejemplo, muy breves. La segunda opción es el modelo de indicaciones. Como regla general en estos casos, se prohíbe abortar en cualquier etapa de la gestación, y con independencia de la voluntad de la mujer, salvo que concurra alguna de las circunstancias expresamente contempladas como fundamento para estimar lícita la conducta, llamadas indicaciones, cuya elección queda a discreción del Legislador en función de criterios políticos, y respecto de las que resulta particularmente importante la determinación de quién es el encargado de verificar su concurrencia. Este sistema, en el que la interrupción del embarazo es esencialmente un acto punible, encaja mejor como forma de positivizar las tesis que se oponen al aborto y defienden una mayor protección del concebido no nacido, pero no necesariamente. Si en un modelo de indicaciones las causas reconocidas para interrumpir el embarazo son muchas o muy amplias, el resultado será una regulación más permisiva, en la práctica, que un modelo de plazo ${ }^{14}$. Todo ello sin olvidar que la concreta caracterización que se haga de la función de asesoramiento a la embarazada (quién debe asesorar y en qué términos) puede condicionar de manera absoluta el funcionamiento del sistema con independencia de las reglas formales o materiales que lo conformen ${ }^{15}$.

\section{LA INTERRUPCIÓN DEL EMBARAZO EN EL ÁMBITO DEL CONSEJO DE EUROPA Y LA UNIÓN EUROPEA}

El Tribunal Europeo de Derechos Humanos se ha pronunciado en varias ocasiones sobre el encaje de la interrupción del embarazo en el Convenio de Roma, si bien manteniendo la neutralidad que le caracteriza siempre que se enfrenta a cuestiones éticamente comprometidas. En el caso Vo contra Francia, de $2004^{16}$, en la línea de resoluciones anteriores que expresamente cita (\$76-79), determina que el concebido no nacido no se incluye por definición dentro del ámbito de protección derecho a la vida, aunque estima que "no es deseable ni siquiera posible actualmente responder en abstracto a la cuestión de si un niño por nacer es una "persona»" en el sentido del art.

\footnotetext{
${ }^{14}$ Ejemplo de esto sería el modelo adoptado, nuevamente, por la Unión Soviética a partir de 1955, que contemplaba hasta 13 indicaciones a las que acogerse para interrumpir legalmente un embarazo.

${ }^{15}$ En relación a la importancia del asesoramiento en los distintos modelos de interrupción voluntaria del embarazo, Vid. ESER, A. "Reforma de la Regulación Alemana sobre el Aborto desde una Perspectiva de Derecho Comparado,", en Actualidad Penal, 4/24, enero de 1994, p. 63 s.

${ }^{16}$ Vo c. Francia [GC], no. 53924/00, ECHR 2004-VIII.
} 
2 CEDH (§85). Por tanto, la articulación de sus garantías jurídicas, que el Tribunal pone en relación con la determinación del inicio de la vida, queda en manos del margen de apreciación de los Estados (§82) a la vista de las divergencias y la falta de consenso existente entre estos acerca de estas cuestiones.

Posteriormente, en la Sentencia de A, B y C contra Irlanda, de $2010^{17}$, el Tribunal sostuvo que el art. $8 \mathrm{CEDH}$ (derecho al respeto a la vida privada y familiar) no puede ser interpretado como el reconocimiento de un derecho al aborto $(\$ 212)^{18}$. La Sentencia reitera la doctrina de 2004, señalando que cada Estado goza de una amplia libertad para establecer la regulación que considere sobre la interrupción del embarazo a partir de sus propios parámetros morales (\$235-237), por lo que no se le puede exigir la adopción de sistemas o soluciones concretas, aunque sí que la implementación del modelo escogido sea coherente y permita tener en cuenta los distintos intereses presentes de manera adecuada $(\$ 249)^{19}$. Por ello, la Sentencia entendió que sí existe vulneración del art. $8 \mathrm{CEDH}$ cuando el Estado no regula la cuestión de manera clara ni permite a la mujer acceder en la práctica a los medios técnicos sanitarios que le permitirían comprobar la concurrencia del riesgo vital (\$250-270) en el caso de que esta circunstancia se contemple como causa legítima para interrumpir un embarazo por cualquier instrumento normativo válido.

Lo paradójico de este fallo es que el propio Tribunal reconoce que sí existe una "mayoría sustancial" que permite aprecia un consenso en Europa en cuanto a establecer sistemas de acceso a la interrupción del embarazo más permisivos que la prohibición absoluta que regía en Irlanda en aquel momento (\$235). Una afirmación así, por lógica, tendría que haber llevado a una aplicación menos estricta de la doctrina del margen de apreciación y, quizá, a reconocer la necesidad de que los Estados miembros del Convenio recojan en sus legislaciones alguna fórmula para la despenalización de la interrupción voluntaria del embarazo, por limitada que fuera, aunque es evidente que una afirmación así habría resultado excesivamente comprometida teniendo en cuenta la corrección política que caracteriza al Tribunal de Estrasburgo.

Considerando esto, no debería sorprender la más actual Sentencia del asunto $P$ y $S$ c. Polonia, de $2012^{20}$, donde a la doctrina consolidada se ha añadido que, una vez que un Estado, actuando dentro de sus límites de apreciación, reconoce la posibilidad de abortar en algunas situaciones, no debe estructurar su marco legal de modo que limite el acceso real a la misma. En particular, "el Estado tiene la obligación positiva de crear un marco de procedimiento que permita a una mujer embarazada ejercer efectivamente su derecho de acceso al aborto legal" (\$99). Esto implica que el procedimiento establecido para la toma de decisiones relevantes al respecto debe ser justo y permitir proteger los bienes sobre los que se proyecta, lo que requiere la participación activa y real de la mujer para defender su posición mediante la posibilidad de ser oída en persona y ver considerados sus puntos de vista, además de poder acceder por escrito a las decisiones de los órganos competentes. En suma, la conclusión que se puede extraer de los fallos

\footnotetext{
${ }^{17}$ A, B y C c. Francia [GC], no. 25579/05, ECHR 2010.

${ }^{18}$ Aunque el derecho a la vida privada y familiar, como manifestó el Tribunal poco antes, sí incluye la obligación de respetar la decisión de un sujeto sobre si tener o no hijos. Vid. Evans c. Gran Bretaña [GC], no. 6339/05, §71, ECHR 2007-IV.

${ }^{19}$ Doctrina ya establecida en la Sentencia del caso Tysiac c. Polonia, no. 5410/03, §116-124 ECHR 2007I.

${ }^{20}$ P y S c. Polonia, no. 57375/08, 30 de octubre de 2012.
} 
del Tribunal Europeo de Derechos Humanos es que cada Estado es libre de plantear el modelo de despenalización del aborto que considere conforme a sus propios pero, una vez hecho, debe asegurar la implementación efectiva del mismo; y todo ello a pesar de que, poco a poco, el Tribunal parece ir abriéndose al reconocimiento como amparable de la posibilidad de interrumpir el propio embarazo de alguna manera,

La Asamblea Parlamentaria del Consejo de Europa se movió en la misma línea pragmática en su Resolución 1607 (2008), “Acceso a un aborto sin riesgo y legal en Europa" ${ }^{21}$. Partiendo de la premisa de que el aborto no es un instrumento de planificación familiar y debe ser evitado en la medida de lo posible, la Asamblea se centró en poner de manifiesto que en aquellos Estados donde se ha despenalizado de alguna manera el acceso efectivo a la prestación, ésta se ve obstaculizado en la práctica, lo que produce una situación de discriminación que debe ser combatida. No entra en el debate sobre la posible existencia implícita de un derecho a interrumpir el embarazo en el articulado del CEDH, pero sí invita a los Estados a "garantizar el ejercicio efectivo del derecho de las mujeres a acceder a un aborto sin riesgo y legal" y a respetar "la libertar de elección de la mujer" a partir de unas condiciones que permitan a la mujer decidir de manera libre y clara y acceder a la prestación sin riesgos; todo ello, eso sí, sin promover la realización de abortos. Considerando además que prohibir la interrupción voluntaria del embarazo no sirve para reducir el número de intervenciones de este tipo, sino para conducirlas a la clandestinidad, invita también a "despenalizar el aborto dentro de unos plazos de gestación razonables si no se ha hecho", junto con la adopción de políticas de mejora de la educación sexual y de acceso a la anticoncepción. Por tanto, una vez que la Legislación nacional ha reconocido esta posibilidad, el Poder Público debe actuar de manera consecuente y garantizar el cumplimiento efectivo de las previsiones normativas en toda su extensión, sean las que sean.

El Parlamento Europeo también se ha pronunciado sobre el fenómeno y la regulación de la interrupción voluntaria del embarazo en los Estados miembros, evolucionando en 11 años desde una postura más moderada hasta un rechazo evidente de la posibilidad de intervenir para articular un desarrollo común del derecho a la salud sexual y reproductiva, prueba de una enorme polarización en las diferentes posturas políticas $^{22}$.

Antes, el Tribunal de Justicia, en relación a la determinación del concepto de embrión humano a efectos de aplicación de la Directiva 98/44/CE ${ }^{23}$, declaró que se entiende incluido en dicha categoría al óvulo humano fecundado ${ }^{24}$, por lo que éste queda excluido de la posibilidad de ser patentado conforme al art. 6.2.c) de la Directiva. Si bien es cierto que el Tribunal vincula su conclusión al respeto a los principios de dignidad humana e integridad personal ${ }^{25}$, lo que establece esta resolución es únicamente la protección de dichos óvulos fecundados frente a su uso industrial o comercial. En ningún momento los magistrados afirman o plantean que el embrión deba

\footnotetext{
${ }^{21}$ Resolución de la Asamblea Parlamentaria del Consejo de Europa 1607 (2008), de 16 de abril de 2008.

22 Sobre esta cuestión, Vid. BALAGUER CALLEJÓN, M.L. "Crónica de la Legislación Europea", en Revista de Derecho Constitucional Europeo, 20, 2013, p. 419-428. Disponible en: http://www.ugr.es/ redce/REDCE20pdf/ReDCE20.pdf

${ }^{23}$ Directiva 98/44/CE del Parlamento Europeo y del Consejo de 6 de julio de 1998 relativa a la protección jurídica de las invenciones biotecnológicas. DOUE nº L 213 de 30/07/1998.

${ }^{24}$ Tribunal de Justicia de la Unión Europea, Asunto C- 34/10, Oliver Brüstle c. Greenpeace eV, 18 de octubre de 2011, § 35 .

${ }^{25}$ Cit. $\$ 32$ y 33 .
} 
ser objeto de protección incondicional o absoluta en relación a la interrupción voluntaria del embarazo, como tampoco esbozan principio alguno que deba regir su regulación en los Estados miembros.

En lo que respecta estrictamente al aborto, la primera Resolución del Parlamento Europeo, de julio de $2002^{26}$, señaló que éste no se debe fomentar como método de planificación familiar, recomendando a los Estados la adopción de "una política sanitaria y social que permita una inflexión del recurso al aborto, concretamente, mediante la prestación de servicios y asesoramiento de planificación familiar y la oferta de ayuda material y económica a las mujeres embarazadas que se encuentren en dificultades", basada en información objetiva y científica y expresada en términos adaptados y de fácil comprensión. Junto a ello, también se recomendaba que, para proteger la salud reproductiva y los derechos de las mujeres el aborto fuera legal, seguro y accesible.

El 26 de septiembre de 2013 la Comisión de Derechos de la Mujer e Igualdad de Género remitió una muy extensa Propuesta de Resolución al Pleno sobre "salud sexual $y$ reproductiva y derechos afines" ${ }^{\prime 27}$. En ella, entre otras cuestiones relacionadas con la protección de la salud sexual y reproductiva de las mujeres en especial, se reivindicaba el derecho de éstas a "decidir libre y responsablemente el número de hijos, así como cuándo y con qué intervalos tenerlos" como un elemento esencial para su desarrollo individual, social y económico. Y para evitar las situaciones de discriminación, sobre todo económica, que se derivan de la existencia de Legislaciones especialmente restrictivas se recomendaba a los Estados miembros la implementación de servicios de interrupción del embarazo de calidad, legales, seguros y accesibles a todas las mujeres dentro de sus sistemas de salud como un objetivo de derechos humanos y salud pública, si bien se explicita que "en ningún caso debe promoverse el aborto como método de planificación familiar". Tras una primera devolución a la Comisión, el Pleno, en sesión de 10 de diciembre de 2013, acabó adoptando, por una mínima diferencia, una propuesta de resolución alternativa que se limita a señalar que "la formulación y aplicación de políticas en materia de salud sexual y reproductiva y derechos afines, así como en materia de educación sexual en las escuelas, es competencia de los Estados miembros" 28 , por lo que la Unión Europea, aunque puede "contribuir a fomentar las mejores prácticas entre los Estados miembros" (sin definir en qué consisten) no puede establecer ni obligaciones ni recomendaciones al respecto para los Estados, y mucho menos pautas regulatorias comunes.

\footnotetext{
${ }^{26}$ Resolución del Parlamento Europeo, de 3 de julio de 2002, sobre salud sexual y reproductiva y los derechos en esta materia.

${ }^{27}$ Informe aprobado por la Comisión de Derechos de la Mujer e Igualdad de Género el 19 de septiembre de 2013, referencia de procedimiento 2013/2040(INI).

${ }^{28}$ Resolución del Parlamento Europeo, de 10 de diciembre de 2013, sobre salud sexual y reproductiva y derechos afines.
} 


\section{EVOLUCIÓN NORMATIVA ANTERIOR A LA CONSTITUCIÓN DE 1978}

\section{De la Edad Media a la Codificación}

Históricamente, desde el final Edad Media se puede apreciar una orientación clara en la regulación de la interrupción del embarazo: su condena como una modalidad de homicidio por parte del Derecho Penal, fuertemente influenciado por la ideología del cristianismo. No obstante, esto sólo sucedía cuando se realizara sobre el feto ya animado, mereciendo menor reproche jurídico en casos de no animación. A este respecto hay que tener en cuenta que la tesis de la animación inmediata del feto en el momento mismo de la concepción es de formulación moderna; en la Edad Media esta cuestión era controvertida para los teólogos, que planteaban diferentes soluciones, diferenciando incluso momentos distintos para la animación en función del género del nasciturus. De la propia Suma Teológica de Tomás de Aquino (s. XIII) se puede inferir que la destrucción del feto por debajo de cierto estadio de desarrollo no es relevante y, por tanto, no debería merecer ni reproche moral ni la contrapartida jurídica del castigo ${ }^{29}$. Esto se evidencia en la forma en la que se recogía el delito de aborto en la Ley VIII del Título Octavo (dedicado a los homicidios) de la VII Partida, texto de aplicación a esta cuestión hasta el siglo XIX. En ella se condenaba como homicida tanto a la gestante que interrumpiera su propio embarazo como a cualquier otro que provocara la pérdida del nasciturus sin contemplar excepciones, pero sí una gradación de la pena en función de si el concebido no nacido estaba o no vivo, es decir, animado ${ }^{30}$.

Ya en la época de la Codificación, sin entrar una descripción detallada de los tipos en cada caso, los sucesivos Códigos Penales contemplaron como delito el aborto, con o sin el consentimiento de la gestante e independientemente de que se lograse el resultado. No se preveía expresamente ninguna circunstancia que permitiera interrumpir legalmente un embarazo aunque sí una atenuante para la mujer que actuara para preservar su honra o imagen ${ }^{31}$. No obstante, existe jurisprudencia de 1876, posteriormente revocada, donde se considera que la vida uterina no está presente en los primeros dos meses de gestación y, por tanto, la destrucción del feto en ese periodo no entraría dentro de la conducta tipificada penalmente, por lo que sería admisible ${ }^{32}$. Tanto la propia forma en la que se planteaban los tipos penales como esta última apreciación

\footnotetext{
${ }^{29}$ El autor plantea, en cierto modo, una visión biológica de la formación del feto: según expone, a medida que éste se desarrolla, Dios introduce distintos tipos de almas en él, cada una sustituyendo a la anterior, y sólo al alcanzar un cuerpo ya formado aparece el alma racional, definitiva (Parte I, Cuestión 76, Art. 3, Ap. 3 y Parte I, Cuestión 118, Art. 2, Ap. 2), no siendo las anteriores distintas de aquellas de los animales o las plantas. De aquí podría inferirse que el no nacido no puede ser considerado "persona" hasta el momento de adquirir esa alma racional y, por tanto, no está vivo como ser humano, por lo que su destrucción no sería condenable. Esto se podría reforzar con otros dos argumentos. En primer lugar, la afirmación de que la vida de los animales y las plantas, no racionales, se conserva sólo para provecho del hombre, a cuyo servicio se encuentran (Parte II-II, Cuestión 64, Art.1). En segundo lugar, porque sólo incurre en delito de homicidio aquel que hiere a una mujer embarazada y causa la muerte de ésta o del "feto animado", es decir, sólo de aquel que posee ya alma racional (Parte II-II, Cuestión 64, Art. 8), no diciéndose nada respecto de las implicaciones de acabar con un feto no animado.

${ }^{30}$ GARCÍA MARÍN, J.M. El aborto criminal en la legislación y la doctrina. Madrid, 1980, p. $43 \mathrm{~s}$.

${ }^{31}$ El CP de 1822 permitía a la gestante ver reducida la pena si su actuación estaba motivada para "encubrir su fragilidad" en caso de mujer soltera o viuda "no corrompida y de buena fama", en opinión del Juez. En el CP de 1848 y posteriores la atenuante se mantiene, pero referida simplemente a la actuación llevada a cabo por cualquier mujer para "ocultar su deshonra", sin referencias a su condición familiar o social ni a su honorabilidad.

${ }^{32}$ ÁlVAREZ CID, J.; ÁLVAREZ CID, T. El Código Penal de 1870, T. II. Córdoba, 1908, p. 196.
} 
jurisprudencial permiten apreciar claramente cómo la impronta de la moral religiosa seguía muy presente en el Derecho en lo que respecta a esta cuestión.

\section{La regulación en la II República}

El cambio más relevante en la regulación de la interrupción del embarazo se produce durante la Guerra Civil, cuando se positiviza por primera vez su posibilidad como una opción de la mujer fuera de la Legislación penal. Antes de nada, se hace preciso apuntar cómo la Constitución de 1931, en su Título III, no reconocía expresamente un "derecho a la vida" en el que anclar hipotéticamente un deber de protección del concebido no nacido en caso de considerarlo titular del mismo. Sí que es cierto que el párrafo $6^{\circ}$ del art. 43 recogía un deber estatal de protección "de la maternidad y la infancia", pero lo hacía en la forma de lo que hoy se denominaría principio rector de la política social ${ }^{33}$. Se trataba un mandato de actuación positiva destinado al Poder Público para que promoviera las medidas necesarias al respecto, cuyo contenido no se condicionaba más allá del hecho de declarar la adhesión a la "Declaración de Ginebra" de 1924 sobre derechos del niño, donde se contenían 5 premisas relativas a la protección y el desarrollo de los menores de edad, especialmente frente a situaciones de desamparo, pero que en absoluto contemplaba la figura del concebido no nacido ${ }^{34}$.

Así las cosas, el Código Penal de 1932 mantuvo esencialmente los tipos penales de los textos precedentes en relación al delito de aborto en sus arts. 417 a 420, aunque con dos importantes novedades: se suprimió la tipificación del aborto culposo o imprudente y se recogió una agravante específica en caso de muerte de la mujer como consecuencia de la práctica de la intervención.

La despenalización efectiva de la posibilidad de interrumpir el embarazo, dejando aparte algún intento infructuoso de alcance nacional, se produjo en Cataluña durante la Guerra Civil. Fue mediante el Decreto de Presidencia de 25 de diciembre de 1936, complementado con la Orden del Departamento de Sanidad y Asistencia Social de 1 de marzo de $1937^{35}$, que conformaban un marco regulatorio un tanto confuso y con ciertas lagunas. Su finalidad, según se decía en la Exposición de Motivos del Decreto, era la de "facilitar al pueblo trabajador una manera segura y exenta de peligro de regular la natalidad cuando existan causas poderosas, sentimentales, eugenésicas o

\footnotetext{
${ }^{33}$ OLIVER ARAUJO, J. “La Constitución republicana de 1931”, en Dereito, Vol. 6, nº1, 1997, p. 113.

${ }^{34}$ Los 5 principios recogidos en la redacción original de la Declaración de 1924 eran:

1. El niño debe ser puesto en condiciones de desarrollarse normalmente desde el punto de vista material y espiritual.

2. El niño hambriento debe ser alimentado; el niño enfermo debe ser atendido; el niño deficiente debe ser ayudado; el niño desadaptado debe ser reeducado; el huérfano y abandonado deben ser recogidos y ayudados.

3. El niño debe ser el primero en recibir socorro en caso de calamidad.

4. El niño debe ser puesto en condiciones de ganarse la vida y debe ser protegido de cualquier explotación.

5. El niño debe ser educado inculcándole el sentimiento del deber que tiene de poner sus mejores cualidades al servicio del prójimo.

${ }^{35}$ Diari Oficial de la Generalitat de Catalunya de 9 de enero de 1937, p. 114 y 115, y de 5 de marzo de 1937, p. 995-998.
} 
terapéuticas que exigiesen la interrupción artificial del embarazo". Para ello, se permitía la práctica de la interrupción del embarazo por razones de tipo terapéutico, eugenésico o ético (art. 2 del Decreto), sin límite de tiempo en el primer caso y con un plazo de 3 meses en los otros dos (art. 4 del Decreto); no obstante, el plazo podía no ser tenido en cuenta si así lo autorizaba una comisión técnica (art. 3.b de la Orden). La intervención debía llevarse a cabo siempre en centros autorizados anexos a hospitales y clínicas, quedando expresamente vetada la práctica privada de abortos (art. 13 del Decreto). Además, era obligatorio un reconocimiento médico previo de la gestante y la realización de una "ficha médica, psicológica, eugenésica y social" (art. 10 del Decreto). Las únicas razones justificadas para negar la prestación a la mujer si estaba en plazo eran la existencia de contraindicaciones médicas o haber sufrido otro aborto durante los doce meses anteriores (art. 3 de la Orden), aunque esto último no se aplicaba si existían razones terapéuticas para realizar la intervención (art. 5 del Decreto).

El contenido de las indicaciones, que se citaban nominalmente, no se definía en ningún momento ni se planteaba mecanismo alguno para verificar su concurrencia una vez alegadas por la mujer. Únicamente se estipulaba la obligación de solicitar a la Consejería un certificado del cumplimiento de los plazos antes de comenzar la exploración previa (art. 16 de la Orden). Es más, el art. 2 de la Orden determinaba que, salvo en los casos terapéuticos, para llevar a cabo la interrupción del embarazo bastaba con la solicitud por escrito de la embarazada con renuncia a reclamaciones futuras ${ }^{36}$, por lo que una lectura conjunta de ambas normas lleva a concluir que, en la práctica, se estaba implementando un modelo de plazo puro en el que las razones terapéuticas constituían un supuesto especial que permitía prescindir de buena parte de los requisitos formales.

Después de la Guerra Civil estas normas son derogadas y la posibilidad de interrumpir el embarazo vuelve a estar prohibida y tipificada como delito, además de perseguirse las prácticas anticonceptivas para, se argumentaba, proteger el interés demográfico del Estado ${ }^{37}$. El Código Penal de 1944, que recogía los preceptos de la Ley de Protección de la Natalidad de 1941, castigaba todo aborto y cualquier otra práctica destinada a destruir el producto de la concepción en el vientre materno con independencia de la viabilidad del feto o del momento de la gestación ${ }^{38}$, manteniendo, eso sí, la atenuante para la mujer que actuara para salvar la propia honra, cuya aplicabilidad se extendía a los progenitores que hicieran lo propio respecto de su hija. La Ley no reconocía expresamente ninguna causa que permitiera interrumpir legítimamente el embarazo pero, de acuerdo con una Circular de la Fiscalía del Tribunal Supremo de 1941, el aborto terapéutico practicado en caso de riesgo vital para la gestante podía admitirse por la vía de la eximente genérica del estado de necesidad, liberando de responsabilidad a los intervinientes ${ }^{39}$. Finalmente, en el CP de 1973 esta

\footnotetext{
${ }^{36}$ Lo cual resultaba en parte contradictorio con el art. 3 del Decreto, donde se otorgaba a la mujer en exclusiva la capacidad para solicitar la intervención en el caso de concurrir razones éticas pero, tácitamente, permitía entender que los familiares podrían sustituir su voluntad para solicitar un aborto por motivos terapéuticos o eugenésicos.

37 MONGE FERNÁNDEZ, A. "Reflexiones jurídico-penales sobre la interrupción voluntaria del embarazo", en VV. AA., Bioética y Derechos Humanos: Implicaciones Sociales y Jurídicas (Coord. por Ruiz de la Cuesta, A.), Sevilla, 2005, p. 248.

${ }^{38}$ CUELlo CALÓN, E. Derecho Penal, T. II. Barcelona, 1955, p. 493. Es llamativo, no obstante, que el autor señala, en p. 491, que estos tipos penales no tienden "a la protección de la persona, pues el feto aún no lo es, no es sujeto de derechos, sino, principalmente, a la protección de un futuro ser humano"

${ }^{39}$ Ibídem, p. 503-504.
} 
cuestión se formuló en términos algo más relajados y, por primera vez, la actuación para salvar la honra no funcionaba como atenuante sino como circunstancia agravante.

\section{EL MODELO DESPENALIZADOR DE LA LO 9/1985}

\section{Descripción del sistema}

Vigente la Constitución de 1978, el CP de 1973 fue modificado mediante la LO 9/1985, de 5 de julio, para añadir un art. 417bis donde se contenían los requisitos que debían concurrir para considerar jurídicamente viable la interrupción de un embarazo. El Proyecto fue objeto de recurso previo de inconstitucionalidad que se resolvió mediante la STC 53/1985, de 11 de abril, donde, pese a validar tanto la finalidad como el fondo de la regulación enjuiciada, ésta se declaró inconstitucional al entender que algunos de los requisitos procedimentales establecidos no cumplían con determinadas exigencias derivadas del art. $15 \mathrm{CE}^{40}$.

Una vez aprobada la Ley, sus disposiciones se mantuvieron vigentes sin modificaciones hasta 2010 en virtud de la Disposición Derogatoria del CP de $1995^{41}$. La teórica vocación provisional de esta previsión se acabó transformando en una situación definitiva a consecuencia del fracaso del Proyecto de LO sobre regulación de la interrupción voluntaria del embarazo que el Gobierno presentó en 1995, donde se contemplaba un sistema de indicaciones, formulado fuera del $\mathrm{CP}$, que sumaba la llamada indicación social a las tres ya vigentes ${ }^{42}$, planteando la opción de interrumpir el embarazo en las primeras 12 semanas, y previo asesoramiento, cuando su continuación supusiera para la mujer un conflicto personal, familiar o social de gravedad.

En el sistema de la LO 9/1985, el aborto se caracteriza, por definición, como una práctica contraria a Derecho que debe ser evitada y sólo será admisible, como excepción al ilícito, si se dan determinadas circunstancias expresamente tasadas. Los casos en los que se permitía interrumpir un embarazo se definían a partir de tres supuestos fácticos descritos a modo de indicaciones a los que se sumaban tres exigencias generales a las que se supeditaba cualquier interrupción lícita del embarazo ${ }^{43}$ : contar con el consentimiento expreso de la gestante, practicar la intervención por un médico o bajo su dirección y hacerlo en un centro sanitario acreditado público o privado. En estas

\footnotetext{
${ }^{40}$ Indicando además el Tribunal, en una obvia extralimitación en sus funciones, cuál debía ser el contenido detallado de la futura regulación de la interrupción del embarazo. Los propios Votos Particulares formulados a la Sentencia coinciden en argumentar con acierto al respecto.

${ }^{41}$ La norma se complementó con el RD 2409/1986, de 21 de noviembre. Antes de su promulgación, el abandonado Proyecto de CP de 1992 contenía un art. 151 que era, en lo sustancial, idéntico al 417bis del CP de 1973.

${ }^{42}$ BOCG, Congreso de los Diputados, Serie A, no 125-1, de 25 de julio de 1995, p. 1-5. A pesar de que el PSOE contaba, al menos en el Congreso, con mayoría para aprobarlo, el Proyecto caducó al disolverse las Cortes Generales en 1996.

${ }^{43}$ LAURENZO COPELLO, P. El aborto en la legislación española: una reforma necesaria, Madrid, 2005, p. 13.
} 
circunstancias, la interrupción del embarazo era una conducta "no punible", expresión que suscitó enormes dudas interpretativas en la doctrina ${ }^{44}$.

La primera de las indicaciones, denominada terapéutica por la doctrina porque, a diferencia del Decreto de 1937, el art. 417bis del CP 1973 describía las indicaciones por su contenido sin atribuirles una denominación, permitía interrumpir el embarazo en cualquier momento por existir un grave peligro para la vida o la salud física o psíquica de la embarazada, que debía medirse en función de las circunstancias de cada caso concreto pero, aunque siempre tenía que ser superior al riesgo propio de cualquier embarazo, el hecho de que ya se hubiera materializado no se consideraba algo imprescindible para invocar la indicación ${ }^{45}$. Independientemente de esto, era la mujer quien, en última instancia y salvo que no se pudiera obtener su consentimiento, debía decidir si se realizaba o no el aborto a partir del dictamen médico, que no podía anteponerse a su voluntad ${ }^{46}$.

La indicación ética hacía referencia al embarazo consecuencia de un delito de violación, permitiendo abortar dentro de las 12 primeras semanas de gestación siempre que el hecho hubiera sido denunciado con el fin de proteger a la gestante de posibles padecimientos emocionales. En tercer lugar, el supuesto denominado eugenésico o embriopático ampliaba a 22 semanas el plazo para abortar si se detectaban, mediante diagnóstico prenatal, graves taras físicas o psíquicas en el feto según criterios de probabilidad valorados conforme a parámetros médicos.

Por encima de valoraciones o dificultades interpretativas, el principal problema del modelo de despenalización del aborto de 1985 era que su implementación no reflejaba la previsión normativa; la facilidad que existía para defraudar las previsiones del sistema lo convertía en ineficaz. Pese a no contemplar expresamente la indicación social como causa de interrupción de la gravidez, en la práctica la formulación de la indicación terapéutica abría una puerta trasera a través del riesgo para la salud psicológica de la mujer, siempre que un informe médico certificara que la continuación del embarazo podía suponer una trastorno grave para la gestante por las consecuencias que tendría, por ejemplo, en su realidad social o económica ${ }^{47}$. El problema es que la apreciación de estas circunstancias dependía, en muchos casos, de que la interesada tuviera los medios económicos para recurrir a un profesional fuera del servicio público o encontrase a alguno que, por solidaridad, convicción o militancia, realizara su informe en esos términos. El resultado de todo esto era un modelo clasista y discriminatorio que,

\footnotetext{
44 El empleo del término "no punible" en el CP de 1973 dividió a la doctrina sobre respecto de la naturaleza jurídica de las indicaciones, como se desarrolla en LAURENZO COPELLO, P. El aborto no punible, Barcelona, 1990, p. 143 s. La mayoría de los autores las definían como causas de justificación, mientras que para otros se trataba de cláusulas de exclusión de la culpabilidad ante una imposibilidad de actuar conforme a Derecho. También se calificaron como excusas absolutorias o, simplemente, como conductas atípicas. El resultado práctico de todas estas interpretaciones es el mismo, pero cada una implica una valoración distinta de la conducta de los profesionales sanitarios y de la gestante.

${ }^{45}$ ROMEO CASABONA, C.M. El médico ante el derecho, Madrid, 1990, p. 342.

${ }^{46}$ MUÑOZ CONDE, F. Derecho Penal. Parte Especial, Valencia, 2004, p. 95.

47 Conforme a los datos estadísticos sobre interrupción voluntaria del embarazo del Ministerio de Sanidad, desde 1998 hasta 2009 los abortos amparados por la indicación terapéutica constituyeron más del $96 \%$ del total de los realizados al año en España sin excepción. Desde la entrada en vigor del modelo de plazo, en los años 2011 y 2012, el porcentaje de abortos realizados por petición de la mujer en el plazo previsto fue, respectivamente, del $89,58 \%$ y del $91,26 \%$, cifras muy similares que, si se suman a las interrupciones motivadas por riesgo vital, arrojan casi los mismos porcentajes de la antigua indicación terapéutica, lo cual puede entenderse como un indicio significativo a este respecto.
} 
de facto, funcionaba como un sistema de plazo restringido por razones económicas frente a la dejación de una Administración que no tenía inconveniente en desentenderse de la prestación en favor del sector sanitario privado.

\section{La valoración del Tribunal Constitucional}

La STC 53/1985 caracterizó la interrupción del embarazo como una situación excepcional y singular de conflicto entre dos valores jurídicos igualmente dignos de protección y que deben ser tenidos en cuenta. Por una parte el concebido no nacido, respecto del que expresamente se señala que no es titular del derecho a la vida según se recoge en la Constitución. Esta conclusión ya se había apuntado desde la doctrina basándose en que no sólo ni de la expresión "todos" ni del proceso de elaboración de la Constitución se puede extraer nada en ningún sentido respecto del nasciturus, sino también por el hecho de que en los debates constituyentes se rechazaron enmiendas que proponían la inclusión expresa del no nacido en el art. $15 \mathrm{CE}^{48}$. No obstante, sí constituye un "bien jurídico constitucionalmente protegido" a partir de ese precepto (FJ $\left.7^{\circ}\right)^{49}$, lo que significa que se beneficiará de unos mecanismos de protección necesariamente más atenuados que los que corresponden a los titulares plenos del derecho fundamental, lo que no obsta para que el Estado deba abstenerse de interrumpir o de obstaculizar el proceso natural de gestación y establecer un sistema legal para su defensa que contemple las normas penales como última garantía $\left(\mathrm{FJ} 4^{\circ}\right)$.

En el otro lado se situaría la dignidad personal que se traduce en una capacidad de "autodeterminación consciente y responsable de la propia vida" que, en el caso de las mujeres, se vincula necesariamente a la maternidad como forma de materializar el libre desarrollo de la personalidad y los derechos a la integridad física y moral, a la libertad de pensamiento, al honor, y a la intimidad personal y familiar y a la propia imagen (FJ $\left.8^{\circ}\right)$.

Dada la relevancia de ambos valores, el conflicto no puede resolverse primando de manera absoluta e incondicional uno de ellos sobre el otro. Al contrario, el Legislador "se ve obligado a ponderar los bienes y derechos en función del supuesto planteado, tratando de armonizarlos si ello es posible o, en caso contrario, precisando las condiciones y requisitos en que podría admitirse la prevalencia de uno de ellos" (FJ $\left.9^{\circ}\right)$. Así, se reconoce que la Ley puede "adoptar cualquier solución dentro del marco constitucional" (FJ $12^{\circ}$ ), que estaría delimitado por la condición del nasciturus como bien constitucionalmente protegido y la dignidad personal de la mujer especialmente concretada en el ámbito de la maternidad como materialización de varios derechos fundamentales. La despenalización de la interrupción del embarazo no es, en sí misma, una medida inconstitucional, porque se caracteriza como la solución a un conflicto entre bienes jurídicos y derechos jurídicamente relevantes irresoluble por otros medios. Pero,

\footnotetext{
48 Sobre esta cuestión en particular, Vid. ARROYO ZAPATERO, L. "Prohibición del aborto y Constitución", en Revista de la Facultad de Derecho de la Universidad Complutense, 3 Extra, p. 195-222 ${ }^{49}$ La STC 75/1984, de 27 de junio, FJ 60, ya calificaba ya a la vida humana en formación como un "bien que constitucionalmente merece protección". Esta doctrina se reitera en las SSTC 212/1996, de 19 de diciembre, FJ $3^{\circ}$, y 116/1999, de 17 de junio, FJ 5º, donde se apunta que los no nacidos no pueden considerarse en el ordenamiento constitucional como titulares del derecho fundamental a la vida, aunque deban ser protegidos como bienes jurídicos constitucionales.
} 
en sentido contrario, sí lo serían tanto un sistema que reconociera el aborto libre e incondicionado como uno que lo prohibiera de manera absoluta, ya que supondrían el sacrificio total de uno de los intereses en juego.

El Fallo tampoco prejuzga la viabilidad constitucional de otras fórmulas de despenalización; señala expresamente la validez en abstracto de las tres indicaciones enjuiciadas (terapéutica, ética y eugenésica) como mecanismo de protección de valores y derechos relevantes de la mujer (FJ $11^{\circ}$ ), pero no concluye que éstas sean las únicas circunstancias en las que la interrupción del embarazo pueda estar justificada ${ }^{50}$, sobre todo teniendo en cuenta que hace recaer en el Legislador la configuración concreta del sistema de despenalización del aborto. De hecho, parece reforzarse la legitimidad de la indicación eugenésica, considerada en abstracto como una medida proporcional para proteger un interés legítimo de la gestante $\left(\mathrm{FJ} 11^{\circ}\right)$, y para cuya operatividad la doctrina ha apuntado múltiples y diversos fundamentos ${ }^{51}$, por lo que cabe preguntarse si el regreso a un sistema de indicaciones debería contemplarla obligatoriamente para ser constitucional.

En cualquier caso, la Sentencia vendría a admitir la constitucionalidad de otros modelos de despenalización del embarazo siempre que sirvan para articular y resolver el conflicto que se da entre los derechos fundamentales a la vida y a la salud que se reconocen a la embarazada, junto con su "derecho de autodeterminación consciente y responsable de la propia vida", que forma parte de su dignidad personal, y la pervivencia del nasciturus como bien jurídico ${ }^{52}$. La conclusión del fallo, y esto es algo determinante a la hora de valorar el modelo vigente, es que el Legislador debe aportar una solución en la que haya ponderado los distintos bienes y derechos en juego, lo cual no permite excluir a priori ni la indicación social ni un sistema de plazos. De hecho, esta fórmula se podría entender como una extensión lógica de la declaración sobre el valor de la dignidad y el derecho a la autodeterminación de la mujer, que sirve como pilar principal para fundamentar la indicación ética, si se considera que todo embarazo no deseado, con independencia de la causa, vulnera de manera grave su dignidad y autonomía $a^{53}$.

\section{EL SISTEMA DE LA LO 2/2010}

La aprobación de la LO 2/2010, de 3 de marzo, de salud sexual y reproductiva y de interrupción voluntaria del embarazo supuso, en términos teóricos, un cambio radical en el tratamiento político-jurídico de esta cuestión, cuya constitucionalidad, visto lo que

\footnotetext{
${ }^{50}$ Vid. Voto Particular del Magistrado Tomás y Valiente a la STC 53/1985, §2: "Muestro mi sustancial conformidad con los términos y razonamientos en ellos expuestos, e incluso ex silentio con lo que allí no se dice, pues no hay en ellos ni en ningún otro pasaje de la Sentencia afirmación alguna que permita suponer que esos y sólo esos tres supuestos o indicaciones son los únicos que el legislador podría declarar no punibles".

51 Vid. REVIRIEGO PICÓN, F. Otro estudio más del aborto. La indicación eugenésica y su fundamentación. Madrid, 1998, p. 21 s.

${ }_{52}$ RUIZ MIGUEL, A. El aborto... cit. p. 89 s.

${ }^{53}$ PÉREZ MANZANO, M. y TOMÁS-VALIENTE LANUZA, C. (2008). "Artículo 15”, en VV. AA. Comentarios a la Constitución Española (Dir. Por Casas Baamonde, M.A.; Rodríguez-Piñero y Bravo Ferrer, M.), Madrid, 2008, p. 314:
} 
se acaba de exponer, no debería suscitar mayores dudas. Se trata de un texto que modifica totalmente el paradigma vigente para este tipo de normas, no sólo porque la interrupción del embarazo se recoge en una Ley separada del Código Penal, sino porque su regulación se formula sin ponerla en relación con la noción de delito e intentando abarcar de modo integral el derecho a la salud sexual y reproductiva mediante la previsión de una serie de objetivos estratégicos en materia de atención sanitaria, información y formación que deben ser materializados por los Poderes Públicos en políticas activas. La interrupción del embarazo queda imbricada dentro una visión más global sobre el ejercicio y las implicaciones de la sexualidad femenina, incluida claramente en la asistencia sanitaria constitucionalmente garantizada, y no como algo aislado.

Pivotando sobre las nociones de salud, en general, y de salud reproductiva y sexual de la Organización Mundial de la Salud ${ }^{54}$, y con el objetivo declarado de reforzar la autonomía de las mujeres, en la que integraría el derecho de disposición del propio cuerpo, se regula un sistema de plazo en el que se atribuye a la gestante la decisión última de recurrir o no a la interrupción de su embarazo. Esta posibilidad se define como un derecho de la mujer que, dada la necesidad de proteger el bien jurídico que constituye el concebido no nacido, está sometido a determinadas condiciones imperativas de ejercicio que se articulan a partir de la concepción del embarazo como un proceso gradual. Además, al caracterizar la interrupción del embarazo como una prestación sanitaria a todos los efectos, la LO 2/2010 no sólo supera ciertas reticencias mostradas al respecto por parte de la doctrina, sino que confirma la plena aplicabilidad de la Ley 41/2002, de 14 de noviembre, básica reguladora de la autonomía del paciente y de derechos y obligaciones en materia de información y documentación clínica a este tipo de intervenciones.

Esto tiene una importante proyección en el ejercicio del consentimiento por parte de la mujer, que se califica, a todos los efectos, como consentimiento informado por los arts. 13 de la LO 2/2010 y 7 del RD 825/2010, de 25 de junio. O en otras palabras, como un ejercicio del derecho a decidir sobre la propia salud, materialización de los derechos a la vida, a la integridad física y a la libertad ideológica y religiosa consecuencia de la capacidad de autodisposición sobre el propio cuerpo ${ }^{55}$, sólo que proyectado sobre el ámbito reproductivo. Y, por tanto, limitado por la presencia del nasciturus que como un bien merecedor de consideración jurídica que trasciende el bienestar físico, psíquico o social de la mujer, está íntimamente relacionado con él hasta el punto de modularlo, pero no lo conforma.

\footnotetext{
${ }^{54}$ Recogidas en el art. 1 de la Ley. La salud se define como "un estado de completo bienestar físico, mental y social, y no solamente la ausencia de afecciones o enfermedades". La salud sexual como "el estado de bienestar físico, psicológico y sociocultural relacionado con la sexualidad, que requiere un entorno libre de coerción, discriminación y violencia". Y la salud reproductiva como "la condición de bienestar físico, psicológico y sociocultural en los aspectos relativos a la capacidad reproductiva de la persona, que implica que se pueda tener una vida sexual segura, la libertad de tener hijos y de decidir cuándo tenerlos". Estos conceptos se recogen en el informe de la OMS "Defining sexual health", realizado en Ginebra entre el 28 y el 31 de enero de 2002 y publicado en 2006.

55 STS, de 12 de enero de 2001, Sala de lo Civil, FJ $1^{\circ}$, reiterada por Sentencias de 11 de mayo de 2001 y de 19 de junio de 2007. Sobre el concepto de derecho a decidir sobre la propia salud, Vid. TARODO SORIA, S. Libertad de conciencia y derechos del usuario de los servicios sanitarios, Bilbao, 2005, p. 311 s.
} 
Como tal, debe otorgarse de manera expresa y por escrito por parte de la gestante mayor de edad o de su representante legal, pudiendo prescindir del mismo sólo en circunstancias excepcionales. En caso de menores de edad, una vez que la regla especial que permitía consentir de manera autónoma a las mayores de 16 años ha sido suprimida mediante la LO 11/2015, de 21 de septiembre, su manifestación de voluntad debe acompañarse necesariamente del consentimiento expreso de sus representantes legales.

El contenido de la información previa, elemento esencial para el correcto ejercicio de este consentimiento, sí está condicionado por las peculiaridades de la intervención. Al inicio del periodo de reflexión de 3 días, la Administración sanitaria debe proporcionar a la mujer información sobre sus derechos, las posibilidades de asesoramiento, las prestaciones y ayudas públicas de apoyo a la maternidad y las consecuencias médicas, psicológicas y sociales que pueden derivar tanto de la prosecución del embarazo como de la interrupción del mismo. Todo de modo objetivo, claro, comprensible y adaptado (art. 17 de la LO 2/2010), porque su finalidad no es influir en la decisión de la embarazada en ningún sentido, sino facilitar una decisión verdaderamente libre y responsable por su parte.

Como regla general, el embarazo podrá interrumpirse en las primeras 14 semanas sin alegar ninguna causa objetiva siempre que se cumplan los requisitos imperativos que condicionan la legalidad de la intervención que se recogen en el art. 14 de la LO 2/2010. Debe mediar el consentimiento expreso de la mujer, pudiendo prescindir de él sólo cuando exista riesgo inmediato grave para su integridad física o psíquica y no sea posible conseguir su autorización, y la intervención tiene que practicarse por un médico especialista (ginecólogo-obstetra, se entiende) o bajo su dirección en un centro sanitario público o privado acreditado. Como último requisito, la intervención sólo puede realizarse una vez transcurrido un periodo de reflexión de 3 días tras la recepción, por parte de la mujer de cierta información relativa a su situación.

Las indicaciones siguen existiendo, pero no como requisitos de acceso a la prestación, sino como causas excepcionales que permiten ampliar el plazo. Frente a la ausencia de limitación temporal de la antigua indicación terapéutica, el art. 15 de la LO 2/2010 permite interrumpir el embarazo en las 22 primeras semanas si existe un peligro grave para la vida o salud de la embarazada o el riesgo de graves anomalías en el feto. Si éstas son incompatibles con la vida o el feto sufre una enfermedad extremadamente grave e incurable en el momento del diagnóstico, confirmado por un comité clínico, el aborto podrá realizarse en cualquier momento de la gestación. En estos casos excepcionales, la Ley sólo otorga expresamente a la mujer la capacidad de decisión final sobre la continuación de su embarazo en caso de anomalías fetales graves o enfermedad incurable, pero no hay razón para no interpretar que también en los demás casos, si su voluntad es continuar con la gestación, ésta prevalecerá sobre las recomendaciones médicas.

Ahora bien, el sistema, en los términos en los que se plantea, no está exento de problemas, alguno de ellos de gravedad tal que pone en entredicho la realización de sus fundamentos teóricos. Esa apuesta por la autonomía y la capacidad de decisión de la mujer como fórmula para articular el acceso a la interrupción del embarazo funcionará adecuadamente en la medida en que previamente se haya materializado correctamente la primera parte de la Ley, y ésta no contiene mecanismos concretos de implementación ni 
de seguimiento o control de esas políticas de garantía y promoción de la salud sexual que menciona. Por otro lado, dado que la indicación terapéutica abarca el riesgo para la salud psicológica de la mujer siempre que sea de entidad suficiente, la falta de mecanismo de control sobre los informes médicos que deben certificarlo puede llevar a la misma situación que existía estando vigente el sistema de indicaciones, sólo que ahora implicará una prolongación del tiempo para poder abortar: frente al plazo general de 14 semanas existirá uno de 22 de acceso restringido en función de la capacidad económica de la solicitante.

Finalmente, la LO 2/2010 establece una restricción práctica en el acceso a la interrupción del embarazo respecto del sistema anterior. La indicación terapéutica ya no puede operar pasadas 22 semanas, dado que es el momento a partir del cual el desarrollo fetal puede continuar de modo artificial fuera del seno materno. Pero esto coloca a la mujer en una posición de desventaja a partir del quinto mes y medio de embarazo, sobre todo en casos de riesgo vital. La Exposición de Motivos señala que en estos casos lo adecuado será proceder con un parto inducido, pero la Ley ni lo plasma en su articulado ni plantea qué sucederá cuando no sea posible actuar de ese modo porque, dada la inviabilidad del feto, la interrupción del embarazo supondrá necesariamente su destrucción ${ }^{56}$. Si pasado ese tiempo la única manera de salvar la vida de la mujer es terminar el embarazo y el feto no es viable, el facultativo que proceda así estará cometiendo un delito conforme al art. $145 \mathrm{CP}$ (aborto cometido fuera de los casos legales), y su única posibilidad para no ser castigado por actuar de una manera que con la anterior regulación sí era posible sería recurrir a la eximente genérica de estado de necesidad.

\section{EL INTENTO DE REFORMA DEL ANTEPROYECTO DE LO PARA LA PROTECCIÓN DE LA VIDA DEL CONCEBIDO DE 2013}

A pesar de tratarse de una iniciativa cuya tramitación fue definitivamente descartada por el propio Gobierno en septiembre de 2014, el Anteproyecto de LO informado por el Consejo de Ministros el 20 de diciembre de 2013 con la finalidad de modificar el régimen jurídico de la interrupción del embarazo en España merece ser objeto de un breve análisis, en cuanto a sus rasgos más notorios, por el evidente cambio que pretendía en relación tanto al modelo regulatorio como al paradigma teórico que lo inspiraba, además de articular una solución discutible para la ponderación de los intereses en conflicto. Su contenido parecía alejarse de las premisas establecidas por la jurisprudencia constitucional y, desde luego, no respondía a las pautas mínimas señaladas por el Tribunal Europeo de Derechos Humanos. La propuesta no sólo no trataba el problema como un conflicto entre bienes jurídicos igualmente respetables y dignos de protección, sino que lo solventaba situando a la mujer en una posición de inferioridad manifiesta respecto a la del concebido no nacido, opción que contradecía la

\footnotetext{
${ }^{56}$ La viabilidad del feto no sólo depende de su tiempo de desarrollo, porque aunque con el estado actual de la técnica un feto de cinco meses y medio puede ser viable de manera sostenida en condiciones normales, también su peso o las circunstancias concretas de la gestación influyen en sus posibilidades. Los fetos de menos de 500 gramos no suelen sobrevivir al nacer, y es posible que, por un crecimiento intrauterino retardado, se alcancen los cinco meses de desarrollo sin lograr ese peso, con lo que se comprometería seriamente su viabilidad (Vid. MOORE, K.L.; PERSAUD, T.V.N. Embriología Clínica, Barcelona, 2008, p. 103).
} 
doctrina precedente y vulneraba la obligación de considerar todos los intereses presentes de manera adecuada que se deriva del CEDH para los Estados al abordar esta cuestión. Lejos de ser una propuesta equilibrada, los excesos en su intención disuasoria habrían puesto en seria duda su constitucionalidad en caso de haber salido adelante en sus términos.

La fórmula del anteproyecto se inspiraba claramente en un modelo, el alemán, que no es trasladable sin más ni se justifica en el Ordenamiento español, pues responde a planteamientos teóricos diferentes, sobre todo considerando la valoración del concebido no nacido y la función que debe cumplir la legislación sobre interrupción del embarazo según el criterio del Tribunal Constitucional alemán ${ }^{57}$, muy distinta a la desarrollada por el español en lo relativo al nivel de protección del que es merecedor el concebido no nacido ${ }^{58}$. Para aquel, la interrupción voluntaria del embarazo merece, como regla general, la consideración de conducta esencialmente injusta durante todo el periodo de gestación, por lo que debe ser prohibida penalmente bajo la premisa de que el nasciturus tiene derecho a la vida y, por tanto, su existencia no puede depender de la decisión de terceros, incluyendo a la madre, ni siquiera durante un breve lapso de tiempo, pues tal cosa resultaría contraria a la prohibición constitucional de infraprotección ${ }^{59}$. Sólo circunstancias excepcionales que trasciendan el umbral del sacrificio exigible podrían motivar la previsión de excepciones a esa regla a modo de indicaciones.

El Anteproyecto retornaba a un sistema de indicaciones, pero basado únicamente en dos casos, que se acompañaban de unos requisitos generales de acceso a la intervención que, en cuanto a su formulación en abstracto, no se separaban de los tradicionalmente regulados para esta intervención, aunque su desarrollo concreto sí contenía diferencias. La indicación ética reiteraba la fórmula y el plazo de 12 semanas de la LO 9/1985 para embarazos que fueran consecuencia de cualquier delito contra la libertad o la indemnidad sexual

La indicación terapéutica, sin embargo, se formulaba en términos particularmente complejos que dejaban abiertas múltiples cuestiones. El aborto sólo sería viable en las primeras 22 semanas cuando fuera necesario para solucionar un grave peligro para la salud de la mujer, tanto física como psíquica, irresoluble por otras vías, debiendo entender por tal un menoscabo importante en la salud de la embarazada, con permanencia o duración en el tiempo valorado según los conocimientos de la ciencia médica en ese momento. Su apreciación previa correspondía a dos profesionales ajenos al centro donde se fuera a practicar la intervención, en lo que parecía una medida antifraude, orientada sobre todo a las instituciones sanitarias privadas. Paradójicamente, no se especificaba que la comprobación sobre la salud de la mujer debiera llevarse a cabo en un centro sanitario, obviando uno de los requisitos procedimentales que la STC 53/1985 consideró de relevancia suficiente como para entender que la formulación original de la indicación terapéutica era inconstitucional ${ }^{60}$, lo que, por lógica, debería

\footnotetext{
57 Para una breve caracterización de lo que supuso la Sentencia de 28 de mayo de 1993 del Tribunal Constitucional alemán (BverfGE 88), se puede consultar DOMINGO, R. "El aborto en Alemania", en Cuadernos de Bioética, 1994/3, p. 213 s.; o STEINER, U. "La controversia constitucional en Alemania sobre la regulación penal del aborto", en REDC, 37, enero-abril 1993, p. 159 s.

${ }^{58}$ CAAMAÑO, F. La garantía constitucional de la inocencia, Valencia, 2003, p. 58.

${ }^{59}$ Ibídem.

60 Vid. STC 53/1985, FJ $12^{\circ}$. Según el Fallo, el concebido no nacido no quedaba suficientemente protegido en el Proyecto de Ley porque la formulación de la indicación terapéutica no preveía la
} 
conducir a la misma consideración respecto del Anteproyecto en los términos en los que se presentó. En cualquier caso, con esta fórmula, se planteaba aumentar el umbral del sacrificio exigido a la embarazada sin solventar cómo actuar en el caso de que las soluciones alternativas distintas al aborto, de empleo preferente, produjeran perjuicios irreparables en la gestante, por lo que cabría plantearse su compatibilidad con el respeto al derecho a la integridad física o psíquica de la mujer, además de su dignidad personal.

No se recogía como tal una indicación eugenésica, aunque sí una especialidad eugenésica dentro de la indicación terapéutica, de complicado acceso y mucho más restringida que las previsiones al respecto reguladas hasta el momento. Las anomalías fetales sólo permitirían interrumpir un embarazo en caso de ser incompatibles con la vida y provocar un grave riesgo para la salud psíquica de la mujer de sufrir un perjuicio permanente e importante, certificado por un especialista ajeno al centro donde se fuera a practicar la intervención y distinto a quien la llevara a cabo, debiendo constar las citadas anomalías. Paralelamente, estas anomalías deben constar en un dictamen firmado por un solo médico, con idénticos requisitos, frente a los dos que se han venido exigiendo hasta este momento ${ }^{61}$. Mientras que las leyes anteriores hablaban de riesgo diagnosticado de anomalías fetales graves, en el Anteproyecto se pedía que éstas ya estuvieran presentes en el momento de autorizar el aborto y además implicaran, textualmente, "la muerte del feto o del recién nacido durante el período neonatal". Las taras físicas o psíquicas no materializadas o que no llegasen a ese extremo, con independencia de su gravedad, la posibilidad de curación o de cómo pudieran condicionar la vida del futuro nacido o de la madre, no permitían recurrir a la interrupción del embarazo. Ni siquiera en el caso de que supusieran la certeza de una vida corta para el niño una vez nacido, lo que supone un segundo ejemplo del aumento del nivel de sacrificio exigido a los progenitores. En tal situación se podría plantear el recurso a la indicación terapéutica general, pero igualmente habría estado restringida por la concurrencia presente o futura de un daño permanente en la salud psíquica de la gestante; la única diferencia era la necesidad de obtener el dictamen de dos médicos, lo que muestra la escasa entidad de esta previsión eugenésica. Junto con esto, se incorporaba un elemento subjetivo en relación a la gestante, los problemas para su salud psicológica, que nunca se consideró en las normas anteriores y podía suponer una dificultad añadida para su aplicabilidad, ya que si las anomalías en el feto no provocaran en la embarazada un trastorno psíquico que pueda considerarse grave y permanente, cosa posible si goza de una especial fortaleza psicológica o a causa de otras circunstancias personales, no cabría la opción de interrumpir legalmente el embarazo en los términos estrictos del Anteproyecto.

Excepcionalmente, la propuesta contemplaba la interrupción del embarazo más allá de las 22 semanas, con los mismos requisitos generales de la indicación terapéutica, en los casos de riesgo vital para la mujer aparecido con posterioridad a su transcurso que no se pueda solventar mediante el parto inducido y cuando no se hubiese detectado, o podido detectar anteriormente con un diagnóstico certero, la anomalía incompatible con la vida del feto. En este segundo caso, no quedaba claro si se exigía la concurrencia de un riesgo o daño para la salud psicológica de la gestante, ni se resolvía si un fallo en

necesidad de un dictamen médico previo a la intervención que constatara su concurrencia y porque no se garantizaba que tanto la comprobación previa del supuesto de hecho del aborto en los casos terapéutico y eugenésico como su realización efectiva se llevarían a cabo en centros sanitarios públicos o privados autorizados.

${ }^{61}$ Hay que considerar que la STC 53/85 no precisó nada sobre los médicos que debían comprobar la causa eugenésica, como sí sucedía con la terapéutica. 
el diagnóstico inicial permitiría o no acceder a esta ampliación del plazo. Además, incomprensiblemente, se prescindía de la intervención del comité clínico que, conforme a la Ley vigente, debe confirmar ese diagnóstico.

Pero más allá de la articulación de las indicaciones, lo más llamativo del Anteproyecto era el mecanismo previsto para conformar el consentimiento de la gestante a partir de la información previa, planteado como un elemento con más capacidad de condicionar y limitar el funcionamiento efectivo del sistema que el propio restablecimiento de las indicaciones que chocaba frontalmente a las pautas marcadas por el TEDH, ya que ni era justo ni permitía a la mujer defender su posición o intereses. El asesoramiento previo a cualquier intervención, cuya objetividad y neutralidad en ningún momento se garantizaban, estaba claramente orientado a promocionar la continuación del embarazo y no a permitir el ejercicio de un consentimiento informado verdaderamente libre, rompiendo la regla general de la información sanitaria establecida por el art. 4.2 de la Ley 41/2002 ${ }^{62}$, lo cual es difícilmente compatible con la autonomía del paciente, principio general e inexcusable de la actividad sanitaria. Expresamente, el objeto del asesoramiento debía ser "la protección de la vida, tanto de la mujer como del no nacido, así como el buen desarrollo del embarazo y la resolución de los conflictos", junto con la idea de que "la vida del no nacido constituye un bien jurídico protegido por la Constitución y que, por ello, el aborto solamente resulta conforme al ordenamiento jurídico en situaciones de excepción reguladas en la legislación, lo que suponía mezclar la doctrina del Tribunal Constitucional español respecto del concebido no nacido con la Sección 219(1) del Código Penal alemán en los términos en los que fue redactada tras la Sentencia de $1993^{63}$. Y ello pese a que obedecen a lógicas de fondo diferentes que son de difícil integración en el mismo planteamiento, ya que, vista la jurisprudencia española, resulta complicado imaginar cómo se podría introducir en el Ordenamiento español ese deber que el Tribunal Constitucional alemán impuso (y el Código Penal recogió) a los facultativos de aquel país de persuadir, o casi coaccionar, a las mujeres para que no interrumpan su embarazo incluso en los casos constatados de riesgo para su salud física o psíquica. En la práctica, esto habría supuesto para el profesional tener que explicar a la embarazada el significado de un concepto jurídico que ni el propio Alto Tribunal ha terminado de precisar con claridad, por no decir que el Anteproyecto olvidaba mencionar que un bien jurídico constitucionalmente protegido puede legítimamente ceder ante otros derechos o bienes, cosa de la que también habría que informar a la embarazada si se pretende actuar con justicia.

Junto con esto, el Anteproyecto contemplaba también la realización de un estudio, a partir de la información facilitada por la mujer, de las circunstancias por las que valoraba la posibilidad de interrumpir su embarazo, acompañado de la orientación sobre el modo de resolver los problemas y conflictos presentados. Este trámite plantea dudas desde la perspectiva del derecho a la intimidad de la mujer ya que su realización, imprescindible para interrumpir el embarazo, habría requerido necesariamente que la gestante accediese a compartir datos personales que posiblemente no revelaría si tuviera

\footnotetext{
${ }^{62}$ Conforme a este artículo, la información clínica, que debe ser verdadera, ayudará al paciente "a tomar decisiones de acuerdo con su propia y libre voluntad".

${ }^{63}$ Según el Código Penal de 15 de mayo de 1871, en su versión de 13 de noviembre de 1998 (BGB1. I, p. 945-3322)., Sección 219(1), antes de abortar la mujer debe ser advertida de que "el niño no nacido tiene su propio derecho a la vida con respecto a ella en todas las etapas del embarazo y que una interrupción del embarazo, por tanto, sólo puede ser considerada legal en situaciones excepcionales, cuando llevar el embarazo a término daría lugar a una carga para la mujer tan grave y extraordinaria que excedería de los límites razonables de sacrificio" (traducción propia).
} 
opción. Por otro lado, de modo indirecto, se está diciendo que se debe intentar convencer a la mujer de que hay otras opciones mejores antes de recurrir al aborto.

En caso de recurrir a la indicación terapéutica, se obligaba a informar a la mujer sobre "los riesgos que la interrupción voluntaria del embarazo puede conllevar para la salud de la mujer y para su maternidad futura", y "los aspectos médicos y psicosociales derivados del diagnóstico realizado sobre la salud de la mujer y del feto, en su caso, así como de las expectativas del desarrollo de la vida del niño". Además de dar más peso a las posibles consecuencias negativas de la intervención, nada se decía de tener que mencionar los posibles peligros de la continuación del embarazo, aparte de no establecerse la deseable objetividad de una información que se plantea de modo abiertamente sesgado y sin consideración a la voluntad de la mujer.

La suma de todas estas cuestiones daba origen a una propuesta que legitimaba la coacción y la vulneración de derechos fundamentales de la mujer (específicamente de su libertad de pensamiento y de su derecho a la intimidad), además de no suponer un mecanismo de ponderación equilibrada de los intereses en juego. Sin entrar en el sesgo que demostraba el propio título de la iniciativa, no se consideraba la capacidad de autodeterminación de la propia vida mediante la maternidad en ningún momento del articulado, con lo que se olvidaba uno de los elementos esenciales del problema manifestados por el Tribunal Constitucional, condicionando los términos de ejercicio de los derechos del paciente para este tipo de intervenciones hasta hacerlos desaparecer en la práctica. Además, no se preveían garantías específicas de acceso efectivo a la prestación en los casos despenalizados. Tampoco se reconocía la posibilidad de recurrir al sector sanitario privado en caso de incapacidad del público; esto habría permitido a cada Comunidad Autónoma plena libertad para decidir cómo actuar al respecto, lo que lleva a una situación de discriminación evidente en caso de que alguna hubiera optado, simplemente, por no contemplar la financiación de esta posibilidad, suponiendo una traba más que, nuevamente, contradice la doctrina más reciente del TEDH respecto de la obligación de garantizar el acceso efectivo a la prestación.

\section{CONCLUSIONES}

La constitucionalidad de una determinada regulación de la interrupción voluntaria del embarazo dependerá de que sus cláusulas permitan equilibrar los distintos intereses en juego sin permitir daños desmedidos en ninguno de ellos. Uno de esos intereses es el concebido no nacido, cuya existencia no es un bien jurídico de valor absoluto y, por tanto, no puede justificar sacrificios desproporcionados en derechos fundamentales de la gestante. Un bien constitucional puede estar sujeto a limitaciones mayores que las imponibles a un derecho, por tanto tendrá que ceder con más facilidad. Por otro lado está el libre desarrollo personal de la mujer y los distintos derechos fundamentales sobre los que éste, como valor consagrado al máximo nivel en sí mismo, se proyecta. El debate ha tendido a olvidar esta segunda parte del conflicto, en buena medida porque, de manera interesada, se ha centrado en la figura del nasciturus, lo que ha llevado a plantear la ponderación fuera de sus justos términos.

Ni el modelo de plazo ni el de indicaciones son en sí mismos inconstitucionales ni tienen por qué suponer una desprotección del concebido no nacido o de la mujer. En 
las indicaciones el aborto se articula a partir de la concurrencia de causas objetivas. En el modelo de plazo, que no es sinónimo de aborto libre, a partir del tiempo de gestación y de la actuación responsable e informada de la mujer ante una situación emocionalmente comprometida. Ambas opciones son aceptables en el Estado de Derecho, por lo que quizá habría que preguntarse cuál arroja mejores resultados en la práctica, o cuál funciona mejor para fijar el marco protector de los valores que se consideren esenciales y comúnmente compartidos mientras permite a las ciudadanas desarrollar el propio proyecto vital a partir de sus convicciones.

La experiencia con el modelo de 1985 ha mostrado que un sistema de indicaciones no especialmente restrictivo no cumple con las expectativas, porque no evitaba la realización de abortos no contemplados dentro de los presupuestos objetivos. Y no hay razón para pensar que un modelo de indicaciones más estricto vaya a conseguir mejor protección del concebido no nacido, aun teniendo en cuenta que es un error centrar el objetivo de la actuación del Poder Público sólo en esta figura. Más bien el resultado será el contrario. Se enviará el problema a la clandestinidad, donde no hay manera de dispensar una protección efectiva al nasciturus en casos en los que sí la merecería. Además generará dos consecuencias perniciosas para la mujer: la desprotección de su salud al recurrir a servicios al margen del sistema sanitario institucional y su discriminación efectiva en el acceso a la prestación, al transformarla en un recurso condicionado por la capacidad económica.

La cuestión, al final, es si el Derecho debe intentar alterar la realidad para adaptarla a determinadas ideas o responder a los hechos con la mejor solución posible. Las mujeres que sufran embarazos no deseados y quieran interrumpirlos encontrarán la manera de hacerlo por muchas trabas que ponga el sistema. Por tanto, si el Estado realmente quiere controlar la cuestión y hacer efectiva tanto la protección del concebido no nacido como la de los intereses de la mujer, debe implementar un sistema donde las pretensiones de éstas puedan encauzarse en su justa medida a través del sistema sanitario sin impedimentos artificiosos.

Y es por esto por lo que el sistema de plazos, dejando aparte insuficiencias puntuales de la LO 2/2010, ofrece una mayor seguridad jurídica. En él, los límites de la actuación posible están más claros y no se obliga a buscar subterfugios. Y no es cierto que con esta norma el concebido no nacido esté desprotegido. En primer lugar porque se impide abortar su desarrollo a partir de la decimocuarta semana de gestación en términos generales y, de manera absoluta, a partir de la vigesimosegunda. Se está otorgando a la vida en formación con más de cinco meses y medio una protección incondicional, una garantía condicionada igual a la del sistema de indicaciones derogado entre las 14 y las 22 semanas y una salvaguarda a partir de la responsabilidad de la mujer en la primera fase del desarrollo. Cuestión distinta es que antes haya que articular los medios para que las interesadas puedan ejercer de manera formada esa responsabilidad, pero eso no es un problema del modelo en abstracto.

Al abordar la interrupción voluntaria del embarazo, el Estado debe buscar una manera efectiva de ponderar los intereses en juego para llegar a la mejor conclusión en cada caso, sea la que sea, otorgando su justo valor a cada elemento. Si, para proteger un bien jurídico constitucional se acepta vulnerar derechos fundamentales se estará atribuyendo al primero un valor específico que no corresponde con su categoría jurídica, además de alterar injustamente el funcionamiento del sistema. Eso es precisamente lo 
que pretendió el Anteproyecto de 2013, donde no sólo se optó por restringir el recurso a la interrupción del embarazo más allá del marco establecido por el Tribunal Constitucional, sino que además se legitimaba la coacción sobre la mujer y se introducían dificultades veladas para que ésta no pudiera llegar a materializar su pretensión en los supuestos despenalizados. Más allá de la subyacente postura paternalista y la absoluta negación de la autonomía de la mujer, cosa que atenta frontalmente contra su dignidad y sus derechos subjetivos, se planteaba un sistema timorato y de inviable encaje en el Ordenamiento cuya puesta en práctica no habría respondido a las previsiones normativas.

\section{BIBLIOGRAFÍA}

ÁlvareZ CID, J.; ÁlvareZ CID, T. El Código Penal de 1870, T. II. Córdoba, 1908.

ARROYO ZAPATERO, L. "Prohibición del aborto y Constitución", en Revista de la Facultad de Derecho de la Universidad Complutense, 3 Extra, p. 195-222.

BALAGUER CALLEJÓN, M.L. "Crónica de la Legislación Europea", en Revista de Derecho Constitucional Europeo, 20, 2013, p. 419-428.

CAAMAÑO, F. La garantía constitucional de la inocencia, Valencia, 2003.

CUELLO CALÓN, E. Derecho Penal, T. II. Barcelona, 1955.

DOMINGO, R. "El aborto en Alemania", en Cuadernos de Bioética, Vol. 5, No 19, 1994, p. 213-220.

DWORKIN, R. El Dominio de la vida, Barcelona, 1998.

ESER, A. "Reforma de la Regulación Alemana sobre el Aborto desde una Perspectiva de Derecho Comparado,", en Actualidad Penal, 4/24, enero de 1994, p. 55-71.

FERRATER MORA, J.; COHN, P. Ética aplicada. Del aborto a la violencia, Madrid, 1982.

FINNIS, J. "Abortion and Health Care Ethics", en VV. AA. Bioethics. An Anthology (Ed. por Kuhse, H.; Singer, P.), Oxford, 1999.

GARCÍA MARÍN, J.M. El aborto criminal en la legislación y la doctrina. Madrid, 1980.

IBÁÑEZ Y GARCÍA-VELASCO, J.L. La despenalización del aborto voluntario en el ocaso del siglo XX, Madrid, 1992.

LAURENZO COPELLO, P. El aborto no punible, Barcelona, 1990.

LAURENZO COPELLO, P. El aborto en la legislación española: una reforma necesaria, Madrid, 2005.

LÓPEZ DE LA VIEJA, M. T. La mitad del mundo (Ética y Crítica feminista), Salamanca, 2004.

MONGE FERNÁNDEZ, A. "Reflexiones jurídico-penales sobre la interrupción voluntaria del embarazo", en VV. AA., Bioética y Derechos Humanos: Implicaciones Sociales y Jurídicas (Coord. por Ruiz de la Cuesta, A.), Sevilla, 2005, p. 245-261. 
MOORE, K.L.; PERSAUD, T.V.N. Embriología Clínica, Barcelona, 2008.

MUÑOZ CONDE, F. Derecho Penal. Parte Especial, Valencia, 2004.

OLIVER ARAUJO, J. “La Constitución republicana de 1931”, en Dereito, Vol. 6, n¹, 1997, p. 107-119.

OVERALL, C. Ethics and Human Reproduction. A Feminist Analysis. Boston, 1987.

PECES-BARBA, G. "Ética pública-ética privada", Anuario de Filosofía del Derecho, XIV, 1997, p. 531-544.

PÉREZ MANZANO, M. y TOMÁS-VALIENTE LANUZA, C. "Artículo 15”, en VV. AA. Comentarios a la Constitución Española (Dir. Por Casas Baamonde, M.A.; Rodríguez-Piñero y Bravo Ferrer, M.), Madrid, 2008, p. 311-339.

REVIRIEGO PICÓN, F. Otro estudio más del aborto. La indicación eugenésica y su fundamentación. Madrid, 1998.

ROMEO CASABONA, C.M. El médico ante el derecho, Madrid, 1990.

RUIZ MIGUEL, A. El aborto: problemas constitucionales, Madrid, 1990.

SINGER, P. Ética Práctica, $3^{\text {a }}$ Ed., Barcelona, 1991.

STEINER, U. "La controversia constitucional en Alemania sobre la regulación penal del aborto", en REDC, 37, enero-abril 1993, p. 159-171.

TARODO SORIA, S. Libertad de conciencia y derechos del usuario de los servicios sanitarios, Bilbao, 2005.

THOMSON, J.J. "Una defensa del aborto" en VV. AA., Debate sobre el aborto. Cinco ensayos de filosofía moral, $2^{\text {a }}$ Ed., Madrid, 1992, p. 9-32.

TONG, R. Feminist Thought. A Comprehensive Introduction, $6^{\text {a }}$ Reimp., Londres, 1997. 